\title{
A cross sectional study examining social desirability bias in caregiver reporting of children's oral health behaviors
}

\author{
Lauren A Sanzone ${ }^{1}$, Jessica Y Lee ${ }^{1 *}$, Kimon Divaris ${ }^{1}$, Darren A DeWalt ${ }^{2}$, A Diane Baker ${ }^{1}$ and William F Vann $\mathrm{Jr}^{1}$
}

\begin{abstract}
Background: Our previous research (Pediatrics 2010:126) found a strong association between caregiver oral health literacy $(\mathrm{OHL})$ and children's oral health status; however, we found a weak association with oral health behaviors (OHBs). We hypothesize that this may be due to social desirability bias (SDB). Our objectives were to compare caregivers' responses to traditional OHB items and newer SDB-modulating items, and to examine the association of caregiver literacy with OHBs.
\end{abstract}

Methods: We performed a cross-sectional study of 102 caregiver-child dyads, collecting data for OHBs using both traditional and new SDB-modulating items. We measured OHL using REALD-30, a validated word recognition test. We relied upon percent agreement and Cohen's kappa $(k)$ to quantify the concordance in caregivers' responses and multivariate log-binomial regression to estimate the impact of $\mathrm{OHL}$ on OHBs.

Results: Caregivers' mean REALD-30 score was 20.7 (SD =6.0), range 1-30. We found an association between OHL and 4 of 8 OHBs examined. A subset of behavior questions compared traditional versus SDB-modulating items: history of bottle-feeding: agreement $=95 \%, k=0.83$ (95\% CL:0.68,0.99); daily tooth brushing: agreement $=78 \%$, $k=0.25$ (95\% CL:0.04,0.46); fluoridated toothpaste use: agreement $=88 \%, k=0.67$ (95\% CL:0.49,0.85). After controlling for caregivers' race, marital status and study site, higher literacy scores remained associated with a decreased prevalence of parental report of "decided not brush the child's teeth because it would be frustrating".

Conclusions: Agreement between responses was high for 2 of 3 behavior items. Item 3 (tooth brushing frequency) revealed discordance, likely due to SDB. Use of the SDB-modulating items appears to yield a better estimate of OHB.

Keywords: Caregivers children, Oral health, Oral hygiene, Health literacy, Oral health literacy, Oral health behaviors, REALD-30, Social desirability bias

\section{Background}

\section{Health literacy}

Health literacy has been defined as "the capacity to obtain, process, and understand basic health information and services needed to make appropriate health decisions" [1]. The ability to interact effectively with our increasingly complex health care system requires a set of skills that is distinct from general literacy skills. These include writing, listening, oral communication, numeracy, and organization. Oral health literacy [1] is an

\footnotetext{
*Correspondence: leej@dentistry.unc.edu

1 Department of Pediatric Dentistry, School of Dentistry, University of North Carolina, 228 Brauer Hall, Chapel Hill, NC, USA

Full list of author information is available at the end of the article
}

extension of the concept into the oral health domain, relating to an individual's ability to appropriately manage their oral health care needs.

The health literacy knowledge base has expanded in recent years, with enormous implications for health care delivery and intervention design. One of the key conclusions from this research has been that interventions are unlikely to result in significant change in individuals' health literacy; however, improvements in patient communication and resultant health knowledge can be realized through enhanced written and multimedia communication, improved provider communication skills, and accommodations in systems of care $[2,3]$.

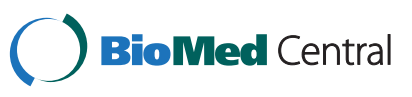




\section{Health literacy and child health outcomes}

It is also known that caregivers' literacy impacts the health of their children. Low health literacy in adult caregivers can affect children's health because children are dependent on their caregivers for access to health care and selfmanagement support [4]. At home, young children need caregivers to perform preventive health behaviors such as toothbrushing and medication administration; older children may be able to perform these behaviors on their own, but still need supervision and encouragement. Additionally, maternal literacy skills have been shown to correlate highly with behaviors that promote health in infants and children, including avoidance of smoking, breastfeeding initiation, and compliance with immunization and preventive care schedules [5,6].

When compared to parents with higher literacy, those with lower literacy demonstrated less health knowledge, and behaviors that were less beneficial to their children's health. Accordingly, children of caretakers with low literacy tend to have worse health outcomes, especially with regard to control of chronic conditions such as asthma and diabetes [7-9]. While the association between parental literacy and children's health outcomes has been explored in depth in the medical literature, these relationships have only recently been examined in the context of dental health [10-12].

The majority of studies exploring the connection between parental literacy and their children's health rely on self-reported behaviors and outcomes. In both research and clinical practice, adherence to preventive regimens is commonly assessed by self-report. However, the integrity of such assessments is contingent on the accuracy of subjects' responses as well as the fidelity with which they report actual behaviors [13]. The validity of self-report measures may be influenced by a variety of factors, including parental recall ability, assessment mode, and social desirability bias (SDB).

\section{Social desirability bias}

SDB is a form of response bias in which individuals misrepresent self-reported behaviors by over-reporting behaviors considered socially desirable, and underreporting undesirable ones [14]. SDB has been most thoroughly investigated in the social sciences, where it is considered one of the most significant and common threats to validity in behavioral sciences research [15]. Unfortunately, the methods utilized to control SDB are highly complex, and no currently available methods are capable of successfully eliminating this source of bias [16].

Although oral health behaviors are hypothesized to be a part of the mechanisms by which literacy can impact oral health status, our previous work found only a weak correlation between caregiver oral health literacy and oral health behaviors [11]. This result raised the question of potential biases, including the possible effects of social desirability bias (SDB), as our analysis used parental selfreported behavioral data. With this backdrop, the specific aims of the current investigation were: (1) to compare caregivers' responses to traditional versus new oral health behavior $(\mathrm{OHB})$ items designed to modulate SDB; and (2) to examine the association of caregiver oral health literacy (OHL) with reported OHBs.

\section{Methods}

\section{Study sample}

This was an IRB-approved cross-sectional study of 102 caregiver-child dyads presenting to a University-based dental clinic and a community-based general health clinic site. A sequential convenience sample of caregiver/child dyads was recruited. Both sites were participants in the Carolina Oral Health Literacy (COHL) Project [10]. Inclusion criteria included healthy children aged 6 years or younger with English-speaking primary caregivers. Children in this age group require more assistance with oral health behaviors, thus their oral health outcomes are more tightly linked to caregiver behaviors. The health literacy instrument utilized has been validated only in English, so only English-speaking caregivers were eligible for the study. Caregiver self-reported OHBs were collected using both traditional and new items designed to modulate SDB.

\section{Data collection procedure}

Our data collection procedures have been described in detail in a previous publication [11]. To summarize, after obtaining written informed consent for study participation, eligible caregivers were asked to complete in-person, verbally-administered surveys by two trained interviewers in a private area. If the primary caregiver experienced any difficulty reading the consent, the interviewer read them aloud. The surveys were verbally administered by two trained interviewers who relied upon a standardized order of data collection as follows: the survey of the caregiver's oral health knowledge, the survey of the child's oral health behavior, the survey of the caregiver's perception of oral health status and the caregiver's literacy instrument. Reliance on this sequence prevented confounding of oral health knowledge, based on the behavior questions. Because the assessment of health literacy can be sensitive for some individuals, the oral health literacy instrument (REALD-30) was administered last.

\section{Variable measurement}

OHBs were caregiver-reported and were assessed in the domains of child oral hygiene and feeding practices. To investigate our SDB hypothesis, we examined three pairs of behavior questions and compared caregivers' responses to traditional and new SDB-modulating items in 
the domains of bottle-feeding, daily tooth brushing, and use of fluoridated toothpaste. The three 'old' behavior questions were time-honored items often found in dental history forms. Although not formally validated, they were introduced in the research arena by Douglass et al. and have been used by others [11,12,17-19]. These traditional questions, which we considered to be more SDB-vulnerable, were paired with reformulated items designed to reduce the impact of SDB. The traditional items asked "Do you clean or brush your child's gums/teeth every day? Responses included 1) yes or 2) no. The new item asked "How often did you help your child brush their gums/teeth? Responses included 1) does not need help, 2) at least 2 times a day, 3) once a day, 3) less than once a day, and 4) once a week. We refer to these new questions as SDB-modulating items. The SDB-modulating items were more indirect. For bottlefeeding, we developed a SDB-modulating item by slightly rephrasing the traditional item. For the use of fluoridated toothpaste, the SDB-modulating item consisted of a multiple choice list that included other means of oral hygiene, as well as non-fluoridated toothpaste. We used identical items for daily brushing along with a new SDB-modulating item. Both the traditional and new SDB modulating items were asked within the same interview.

We measured caregivers' oral health literacy using REALD-30, a validated word recognition test [20]. This instrument is comprised of 30 words used in dentistry, arranged in order of increasing difficulty. Administration of the REALD-30 requires the caregiver to read the words aloud to the interviewer. Caregivers are asked not to try to pronounce words they do not know, but simply to skip words that are not familiar. To score the test, one point is assigned for each word pronounced correctly, and the points are summed to give a total score. The total score can range from 0 (lowest literacy) to 30 (highest literacy).

Demographic data included caregiver race, age, education, number of children, marital status, household income, and study site. Race was self-classified as white, African American, Latina, or Asian. Age was categorized as a quartile-categorical variable. Education was coded as a four-level categorical variable where 1: did not finish high school, 2: high school completion or General Education Diploma (GED), 3: some technical or college education, and 4: college degree or higher. For descriptive purposes, marital status was coded as married, separated/divorced, or single/never married and as a dichotomous (married vs. single/never married/ separated/divorced) for analytical purposes. Household income was grouped in three categories and was coded as $1: \leq \$ 10,000,2: \$ 10,001-29,999$, and $3: \geq \$ 30,000$.

\section{Analytical approach}

Descriptive and summary estimates [simple proportions, mean, range, and standard deviation (SD)] were used for initial data presentation. The normality assumption of OHL scores was tested using a combined kurtosis and skewness $\mathrm{X}^{2}$ test [21]. To investigate the association of $\mathrm{OHL}$ with socio-demographic characteristics and OHBs, we first used analysis of variance (ANOVA) and a $p<$ 0.05 criterion to evaluate OHL differences at the bivariate level. To quantify the association between OHL and parental report of "not brushing child's teeth because it would be frustrating" we employed multivariate analysis based on log-binomial modeling. The selection of a logbinomial over a logistic model was based on the $>20 \%$ frequency $(24 \%)$ of the modeled outcome. Selection of covariates was based on bivariate testing results and evidence from the literature, whereas in the final model this was determined by a $10 \%$ change-in-estimate criterion of the OHL coefficient. We chose the change-in-estimate vs. a statistical significance criterion for the final modelbuilding, because the former method has been shown to perform better under most conditions for control of confounding [22].

To illustrate the extent of agreement and the direction of discordance, we cross-tabulated responses to the above pairs of questions. For ease of interpretation, categories were collapsed and missing observations discarded to create $2 \times 2$ tables, as illustrated in the Additional file 1. We quantified the agreement between responses by calculating percent agreement (PA) and Cohen's kappa statistic and 95\% confidence limits (CL) obtained with bootstrapping (10,000 repetitions). We considered kappa in addition to PA because it quantifies the agreement beyond what would be expected by chance alone $[23,24]$. All analyses were conducted with Stata 11.2 (StataCorp LP, College Station, TX).

\section{Results}

Our analytical sample consisted of 102 caregivers with mean age of 31 years (median 30 years). Sociodemographic characteristics and stratified OHL scores are presented in Table 1. Half of the caregivers were African American, half were married, and two-thirds had annual household income of less than $\$ 30,000$. The mean REALD-30 score was non-normally distributed $\left(\mathrm{X}^{2}=11.3\right.$; $\mathrm{df}=2 ; \mathrm{p}<0.05)$ with mean $20.7(\mathrm{SD}=7.0)$ and median of 22. We observed marked gradients in the OHL within levels of the examined covariates, particularly with regard to education $(\mathrm{p}<0.0005)$ and income $(\mathrm{p}=0.001)$. For example, the mean score was 14.7 among caregivers who had not finished high school vs. 18.0 among those with high school diploma or GED and 25.2 among those with college or higher education. Similarly, caregivers with household income of more than $\$ 30,000$ had 5.9 points higher REALD-30 score compared to those with less than $\$ 10,000$. We also noted marked racial differences with non-whites having a substantially lower 
Table 1 Distribution of Oral Health Literacy (OHL) scores by demographic characteristics among the participating caregiver-child dyads $(n=102)$

\begin{tabular}{|c|c|c|c|c|c|}
\hline & \multirow[t]{2}{*}{$\mathrm{n}^{*}$} & \multirow[t]{2}{*}{$\%$} & \multicolumn{2}{|c|}{ OHL (REALD-30) } & \multirow{2}{*}{$\begin{array}{l}\text { ANOVA F value; } \\
\text { (df1, df2), p }\end{array}$} \\
\hline & & & Mean (SD) & Median (range) & \\
\hline Race & & & & & $12.2 ;(2,99) ; p<0.0005^{\dagger}$ \\
\hline White & 36 & 35 & $24.5(4.6)$ & $26(14-30)$ & \\
\hline African American & 49 & 48 & $17.6(7.8)$ & $18(1-29)$ & \\
\hline Other & 17 & 17 & $21.6(4.6)$ & $21(13-30)$ & \\
\hline Education & & & & & 13.0; $(3,98) ; p<0.0005^{\dagger}$ \\
\hline Did not finish high school & 17 & 17 & $14.7(8.7)$ & $14(1-30)$ & \\
\hline High school diploma of GED & 27 & 26 & $18.0(6.9)$ & $20(2-29)$ & \\
\hline Some technical or college & 36 & 35 & $22.8(4.8)$ & $24(13-30)$ & \\
\hline College degree or higher & 22 & 21 & $25.2(3.8)$ & $25.5(28-30)$ & \\
\hline Number of children & & & & & $0.5 ;(3,94) ; p=0.7$ \\
\hline 1 & 28 & 29 & $19.6(6.0)$ & $20.5(2-29)$ & \\
\hline 2 & 40 & 41 & $20.1(7.7)$ & $22(1-30)$ & \\
\hline 3 & 20 & 20 & $21.2(6.7)$ & $22(5-30)$ & \\
\hline 4 or more & 10 & 10 & $22.4(7.7)$ & $25(2-28)$ & \\
\hline Marital status & & & & & $6.7 ;(2,99) ; p=0.002^{\dagger}$ \\
\hline Married & 49 & 48 & $23.2(5.2)$ & $24(13-30)$ & \\
\hline Separated/Divorced & 6 & 6 & $20.3(9.1)$ & $24(2-26)$ & \\
\hline Never married or single & 47 & 46 & $18.2(7.6)$ & $21(1-30)$ & \\
\hline Household income & & & & & $7.4 ;(2,98) ; p=0.001^{\dagger}$ \\
\hline$\leq \$ 10,000$ & 40 & 40 & $18.1(7.5)$ & $19.5(1-29)$ & \\
\hline$\$ 10,001-30,000$ & 27 & 27 & $20.0(6.3)$ & $22(2-30)$ & \\
\hline$>\$ 30,000$ & 34 & 34 & $24.0(5.6)$ & $26(4-30)$ & \\
\hline Site & & & & & $5.3 ;(1,100) ; p=0.02^{\dagger}$ \\
\hline WIC clinic & 55 & 54 & $19.3(7.4)$ & $22(1-29)$ & \\
\hline Dental School clinic & 47 & 46 & $22.4(6.3)$ & $24(4-30)$ & \\
\hline Age quartiles (years) & & $\underline{\text { Mean(SD) }}$ & & & 3.6; $(3,95) ; p=0.02^{\dagger}$ \\
\hline Q1 (range: 18.2-25.5) & 25 & $22.6(2.0)$ & $17.7(5.8)$ & $18(5-27)$ & \\
\hline Q2 (range: 25.7-30.0) & 25 & $27.5(1.2)$ & $20.0(7.6)$ & $21(1-29)$ & \\
\hline Q3 (range: 30.3-34.6) & 25 & $32.6(1.3)$ & $22.0(6.2)$ & $24(4-30)$ & \\
\hline Q4 (range: 35.3-63.9) & 24 & $42.2(6.8)$ & $23.5(6.6)$ & $25(2-30)$ & \\
\hline
\end{tabular}

*column totals may not add to total due to missing data; ${ }^{\dagger}$ denotes a statistically significant association.

mean REALD-30 when compared to whites [mean = 24.5 $(\mathrm{SD}=4.6)]$ : African Americans-17.6 (SD = 7.8); others21.6 (SD = 4.6); ANOVA $\mathrm{p}<0.0005]$. The number of children was the only covariate not showing a strong relationship with OHL scores.

The contrast of the three pairs of old and new questions is presented in Table 2. Agreement was high for history of bottle-feeding [PA $=95 \%$; kappa $=0.83(95 \%$ $\mathrm{CL}=0.68,0.99)]$ and use of fluoridated toothpaste [PA = $88 \%$; kappa $=0.67(95 \% \mathrm{CL}=0.49,0.85)]$ but was lower for daily tooth brushing $[\mathrm{PA}=78 \%$; $\mathrm{kappa}=0.25(95 \%$ $\mathrm{CL}=0.04,0.46)]$.
The new $\mathrm{OHB}$ items were used to assess the relationships between OHL and OHBs. Analysis of the association between $\mathrm{OHL}$ and behavioral covariates is presented in Table 3. Strong correlations were observed between REALD-30 scores and use of bottle feeding, as well with bedtime bottle or sippy cup usage. Parents with lower REALD-30 scores were more likely to report being frustrated "every time" or "never" when trying to clean their child's teeth, and were more likely to report forgoing oral hygiene efforts due to frustration.

Table 4 presents results of the multivariate analysis quantifying the association between $\mathrm{OHL}$ and the 
Table 2 Contrast and agreement [percent agreement (PA), and Cohen's kappa and 95\% confidence limits $\left(\mathrm{CL}^{*}\right)$ ] of caregivers' responses between the three 'old' and 'new' Social Desirability Bias (SDB)-modulating items pertaining to child oral health-related behaviors

\begin{tabular}{|c|c|c|c|c|c|c|c|c|}
\hline \multirow[b]{2}{*}{$\begin{array}{l}\text { New item }{ }^{\dagger}: \text { How often did you help } \\
\text { your child brush their gums/teeth? }\end{array}$} & \multicolumn{2}{|c|}{$\begin{array}{l}\text { Old item: Do you clean or } \\
\text { brush your child's gums/teeth } \\
\text { every day? }\end{array}$} & \multirow[b]{2}{*}{$\begin{array}{l}\text { New item: Used toothpaste with } \\
\text { fluoride to clean child's teeth }\end{array}$} & \multicolumn{2}{|c|}{$\begin{array}{l}\text { Old item: Do you use } \\
\text { toothpaste when brushing } \\
\text { your child's teeth? }\end{array}$} & \multirow[b]{2}{*}{$\begin{array}{l}\text { New item: How often was } \\
\text { your child fed with a bottle? }\end{array}$} & \multicolumn{2}{|c|}{$\begin{array}{l}\text { Old item: Was } \\
\text { your child fed } \\
\text { with a bottle? }\end{array}$} \\
\hline & Yes & No & & Yes & No & & Yes & No \\
\hline Does not need help & 7 & 0 & Yes & 66 & 6 & More than 1 night/week & 81 & 4 \\
\hline At least 2 times/day & 45 & 1 & No & 5 & 16 & Never & 0 & 11 \\
\hline Once a day & 20 & 2 & & & & & & \\
\hline Less than once a day & 12 & 6 & & & & & & \\
\hline \multirow[t]{3}{*}{ Once a week } & 5 & 0 & & & & & & \\
\hline & \multicolumn{2}{|c|}{$P A=78 \%$} & & \multicolumn{2}{|c|}{$\mathrm{PA}=88 \%$} & & \multicolumn{2}{|c|}{$P A=95 \%$} \\
\hline & \multicolumn{2}{|c|}{$\begin{array}{c}\text { Kappa }(95 \% C L)=0.25 \\
(0.04-0.46)\end{array}$} & & \multicolumn{2}{|c|}{$\begin{array}{c}\text { Kappa }(95 \% C L)=0.67 \\
(0.49-0.85)\end{array}$} & & \multicolumn{2}{|c|}{$\begin{array}{l}\text { Kappa }(95 \% \mathrm{CL}) \\
=0.83(0.68-0.99)\end{array}$} \\
\hline
\end{tabular}

*obtained with bootstrapping ( $\mathrm{n}=10,000$ repetitions); to enable the calculation of PA and kappa from a $2 \times 2$ table the question was converted to a binary item where: "at least 2 times/day" and "once a day" corresponded to "yes" and "does not need help", "less than once a day" and "once a week" corresponded to "no". 
Table 3 Distribution of Oral Health Literacy (OHL; REALD-30) scores by child oral health-related behaviors among the participating caregiver-child dyads $(n=102)$

\begin{tabular}{rccccc}
\hline & $\mathbf{n}^{*}$ & $\%$ & & OHL (REALD-30) & ANOVA \\
& & & Mean (SD) & Median (range) & F value; (df1, df2), $\mathbf{p}$ \\
\hline Did you ever get frustrated trying to clean your child's teeth? & 11 & 11 & $16.5(7.4)$ & 3.2; $(3,98) ; p=0.03^{\dagger}$ \\
Every time & 32 & 31 & $22.8(5.9)$ & $23.5(10-30)$ \\
Sometimes & 9 & 9 & $23.6(4.3)$ & $25(13-28)$ \\
Hardly ever & 50 & 49 & $19.8(7.5)$ & $22(1-30)$ &
\end{tabular}

Did you ever decide not to clean his/her teeth because it would be frustrating?

$4.7 ;(1,100) ; p=0.03^{+}$

$\begin{array}{lllll}\text { Yes } & 24 & 24 & 18.0(7.6) & 18(2-30) \\ \text { No } & 78 & 76 & 21.5(6.7) & 23(1-30)\end{array}$

${ }^{\ddagger}$ How often did you help your child clean/brush their gums/teeth?

$\begin{array}{rccc}\text { At least } 2 \text { times/day } & 48 & 47 & 19.9(7.7) \\ \text { Once a day } & 23 & 23 & 21.0(6.5) \\ \text { Less than once a day } & 23 & 23 & 21.0(6.5) \\ \text { Does not need help } & 8 & 8 & 23.0(5.1)\end{array}$

If your child brushed their own teeth by themselves, how often did they brush?

$\begin{array}{rllll}\text { At least } 2 \text { times/day } & 33 & 32 & 21.1(6.8) & \text { 22(4-30) } \\ \text { Once a day } & 20 & 20 & 20.4(7.9) & 21.5(2-30) \\ \text { Less than once a day } & 15 & 15 & 22.5(4.8) & 22.5(14-30) \\ \text { brush on his/her own } & 34 & 33 & 19.7(7.6)\end{array}$

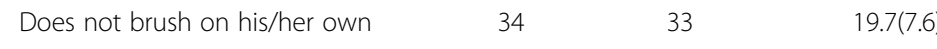

How many times a week did your child go to bed with a bottle or sippy cup?

$\begin{array}{rlccc}\text { Every night } & 13 & 13 & 20.9(5.1) & \text { 21(24-29) } \\ \text { Less than every night } & 11 & 11 & 21.2(6.4) & \text { 23(7-30) } \\ \text { Used to, but stopped } & 26 & 25 & 17.3(8.2) & \text { 24(4-30) }\end{array}$

$\begin{array}{lllll}\text { Never goes to bed with a bottle } & 51 & 50 & 22.3(6.5) & \text { 24(4-30) }\end{array}$

How often did your child use a sippy cup?

$\begin{array}{rccc}\text { At least 2 times/day } & 43 & 42 & 21.6(5.6) \\ \text { Once a day or less frequently } & 9 & 9 & 20.9(7.1) \\ \text { Does not use a sippy cup } & 50 & 49 & 19.9(8.1)\end{array}$

${ }^{\ddagger}$ Was your child fed with a bottle?

$\begin{array}{llll}\text { Yes } & 89 & 87 & 20.0(7.1) \\ \text { No } & 12 & 12 & 26.2(3.5)\end{array}$

$\begin{array}{rrrr}0-6 \text { months } & 16 & 17 & 21.9(7.3) \\ 7-12 \text { months } & 47 & 49 & 18.7(7.7) \\ 13-18 \text { months } & 16 & 17 & 23.3(3.3) \\ 19+\text { months } & 16 & 17 & 20.6(6.4)\end{array}$

What did you use to clean your child's teeth?

$\begin{array}{rlll}\text { Toothbrush only } & 60 & 59 & 19.8(7.1) \\ { }^{*} \text { Fluoridated toothpaste } & 76 & 75 & 20.7(7.5)\end{array}$

${ }^{*}$ column totals may not add to total due to missing data; $\uparrow$ denotes a statistically significant association; ${ }^{*}$ denotes items that were used in the SDB analysis; 9 no formal statistical analysis was conducted for this item which allowed for multiple possible responses.

prevalence of caregiver report of "decided not to brush the child's teeth because it would be frustrating". Among the variables that were evaluated as confounders in models B and C (age, race, education, income, number of children, study site) only race, marital status and study site met the $10 \%$ change-in-estimate criterion for 
Table 4 Multivariate log binomial regression modeling results of caregiver report "Decided not to brush my child's teeth because it would be frustrating" [(adjusted prevalence ratio (PR) and $95 \%$ confidence limits $\left.{ }^{*}(C L)\right]$ on Oral Health Literacy (OHL) among the WIC/UNC participants $(n=102)$

\begin{tabular}{lcccc}
\hline & $\begin{array}{c}\text { Model A } \\
\text { PR (95\% CL) }\end{array}$ & $\begin{array}{c}\text { Model B } \\
\text { PR (95\% CL) }\end{array}$ & $\begin{array}{c}\text { Model C } \\
\text { PR (95\% CL) }\end{array}$ & $\begin{array}{c}\text { Model D } \\
\text { PR (95\% CL) }\end{array}$ \\
\hline Oral health literacy (REALD-30 score) ${ }^{\dagger}$ & $0.96(0.92,0.99)$ & $0.96(0.92,0.99)$ & $0.95(0.92,0.98)$ & $0.94(0.89,0.98)$ \\
Age (years; quartiles) & & $1.24(0.88,1.74)$ & & \\
Site (referent: University clinic) & & & &
\end{tabular}

Race (referent: Whites)

Marital status (referent: married)

Single/never married/separated/divorced

*confidence limits were based on robust standard errors; testimate corresponds to one-unit change in REALD-30 score; $\neq$ denotes the 'final' Model; the education, income, and number of kids variables did not meet the $10 \%$ change-in-estimate criterion and thus were not included in the final model (Model D).

inclusion in the final model (Model D). Using this final model (D) it was evident that while controlling for caregivers' race and study site, one-unit increase in OHL corresponded to a $6 \%$ decrease in caregiver report about frustration (adjusted $\mathrm{PR}=0.94 ; 95 \% \mathrm{CL}=0.89,0.98$ ).

\section{Discussion}

The major aims of this investigation were to 1 ) examine SDB in caregiver reports of preventive oral health behaviors, and 2) examine the association between OHL and oral health behaviors. We found evidence of SDB in 2 of 3 examined behaviors, with the greatest discordance in the item regarding toothbrushing frequency. Using indirect questioning methods appears to mitigate SDB and provide a better estimate of oral health behaviors. Dental caries is a common chronic disease of childhood, and its prevention for young children hinges upon caregiver assistance with OHBs. For this reason, accurate assessment of caregiver-reported OHBs is essential in developing interventions to reduce dental disease in children.

Although the influence of SDB on self-reported health behaviors has long been recognized, research on the impact of SDB in medicine and dentistry has been limited by the methodological difficulties of detecting, quantifying, and controlling this form of bias. To date, much of the published literature has focused on the effects of SDB on dietary self-reports, or on highly sensitive behaviors such as smoking, sexual conduct, and illicit drug usage [25-29]. In these settings, the tendency of individuals to answer in socially desirable ways, as measured by social desirability scales, has been positively associated with self-reported preventive health behaviors in both adults and children [27]. Sjöstrom and Holst investigated the impact of SDB on response error in a dental questionnaire, comparing self-reported levels of preventive dental visits to insurance claim data in a Swedish population. Differences between reported and actual dental attendance ranged from 4.4-42.7\%. Perhaps more importantly, individuals overstated their reported number of dental visits by a greater amount when their actual level of attendance deviated more significantly from the social norm [30]. Thus, individuals appeared to be fully aware of the norm, modifying their responses in such a way as to minimize reporting of socially undesirable behaviors.

Previous investigations relied on individual self-reports to examine SDB. Our study is unique in that we examined SDB in caregiver-reported behaviors. It has been noted that multi-item, indirect responses may modulate social desirability bias compared to binary response items. Our study was the first to develop such multi item indirect responses. In pediatric practice, we often depend on caregiver-reported behaviors to provide accurate risk assessment; accordingly, understanding the effects of SDB on caregiver self-reports is an important aspect of providing timely and appropriate anticipatory guidance.

Our results confirmed the association between lower literacy and deleterious OHBs, as previously reported $[11,12]$. This was evident in 4 of 8 OHBs examined relating to oral hygiene and feeding practices. Although a formal statistical analysis was not conducted for a 9th item that allowed multiple responses with regard to means of cleaning a child's teeth, we observed that caregivers who responded 'fluoridated toothpaste' had on average one point higher REALD-30 score compared to those who responded "toothbrush only". We were struck by the strength of the association between literacy and avoidance of tooth brushing due to frustration. Anecdotally, some of the frustration experienced by parents appears to stem from a lack of information from health care providers regarding practical aspects of performing 
oral hygiene behaviors. Today, parents who perceive a lack of knowledge often turn to the internet or other social media sources [31,32], where a multitude of parenting blogs and web boards provide such shared information. Frustration appears to be a barrier preventing some parents from consistently performing oral hygiene tasks. As current pediatric dental interventions typically fail to address the psychological aspects of parental hygiene assistance, this represents an opportunity to strengthen caregiver oral health education and anticipatory guidance.

These results should be interpreted in consideration of the study's limitations. Word recognition tests, such as the REALD-30 and the REALM, assess reading ability and have been shown to be reliable proxies of literacy in English speakers [20,33-35]. However, these instruments are not capable of assessing the wide array of skills that comprise health literacy, including health knowledge, numeracy, and receipt of information via other modes of communication. Because REALD-30 has been validated only in English, we were unable to recruit non-English speaking respondents.

Given these limitations, we believe there were several strengths in our study. One is the use of trained examiners to administer in-person interviews for data collection. Although the effects of SDB on self-report measures may never be completely eliminated, there is some evidence that face-to-face interviews yield more accurate responses than self-administered computer interviews or paper questionnaires [13]. This interview mode also eliminates the need for participants to read the questionnaire, diminishing the potential for inaccurate responses secondary to insufficient reading skills. Additionally, since low literacy can be a source of sensitivity or shame for individuals, the REALD-30 is administered at the end of the interview process to minimize the potential for bias induced by psychological distress related to literacy measurement.

\section{Conclusion}

Under the conditions of this study, we found evidence of SDB in caregiver-reported OHBs. Use of SDB-modulating items to elicit information regarding dental behaviors may yield more accurate information in some dimensions, such as toothbrushing. However, information on the effects of SDB on oral health selfreports remains incomplete. Future studies should explore the impact of SDB on self-reported preventive behaviors, and how survey items may be designed to minimize this form of bias.

\section{Ethics committee}

This study was approved by the UNC Biomedical Institutional Review Board.

\section{Additional file}

Additional file 1: Model of $2 \times 2$ table used to illustrate the extent of agreement and the direction of discordance between old, traditional OHB items and new, SDB-modulating items.

\section{Abbreviations}

OHBs: Oral health behaviors; OHL: Oral health literacy; OHS: Oral health status; REALD-30: Rapid estimate of adult literacy in dentistry-30; SDB: Social desirability bias.

\section{Competing interests}

The authors declare that they have no competing interests.

\section{Authors' contributions}

LS was the lead author and coordinated the design, data collection and writing of the investigation. $J$ is LS is mentor and principal investigator of the overall research project. She was involved with every aspect of the project from implementation, design, execution and writing of the manuscript. KD conducted the data analysis, assisted with interpretation of the results and writing of the manuscript. DD assisted in interpretation of the data and writing of the manuscript. DB coordinated and conducted data collection. W assisted in interpretation of the data and writing of the manuscript. All authors read and approved the final manuscript.

\section{Acknowledgments}

This study was supported by National Institute of Dental and Craniofacial Research grant \#R01DE018045. Preliminary findings were reported at the International Association for Dental Research General Session in San Diego, CA, March 14-19, 2011

\section{Author details}

${ }^{1}$ Department of Pediatric Dentistry, School of Dentistry, University of North Carolina, 228 Brauer Hall, Chapel Hill, NC, USA. ²Division of General Internal Medicine, School of Medicine, University of North Carolina, 5041 Old Clinic Building, CB\#7110 Chapel Hill, NC, USA.

Received: 15 January 2013 Accepted: 17 May 2013

Published: 1 June 2013

\section{References}

1. National Institute of Dental and Craniofacial Research, National Institute of Health, U.S. Public Health Service, Department of Health and Human Services: The invisible barrier: literacy and its relationship with oral health. A report of a workgroup sponsored by the national institute of dental and craniofacial research, national institute of health, U.S. Public health service, department of health and human services. J Public Health Dent 2005, 65(3):174-182.

2. Doak C, Doak L, Root J: Teaching patients with low literacy skills. 2nd edition. Philadelphia: JB Lippincott; 1996.

3. Seligman HK, Wallace AS, DeWalt DA: Developing low-literacy patient educational materials to facilitate behavior change. Am J Health Behav 2007, 31(Suppl):S69-S78.

4. DeWalt DA, Hink A: Health literacy and child health outcomes: a systematic review of the literature. Pediatrics 2009, 124(Suppl 3):S265-S274.

5. Sanders LM, Thompson VT, Wilkinson JD: Caregiver health literacy and the use of child health services. Pediatrics 2007, 119(1):e86-e92.

6. Zarcadoolas C, Pleasant A, Greer DS: Understanding health literacy: an expanded model. Health Promot Int 2005, 20(2):195-203.

7. Davis TC, Frederickson DD, Potter L, Brouillette R, Bocchini AC, Williams MV, Parker RM: Patient understanding and use of oral contraceptive pills in a southern public health family planning clinic. South Med J 2006, 99(7):713-718.

8. DeWalt DA, Dilling MH, Rosenthal MS, Pignone MP: Low parental literacy is associated with worse asthma care measures in children. Ambul Pediatr 2007, 7(1):25-31.

9. Kripalani S, Henderson LE, Chiu EY, Robertson R, Kolm P, Jacobson TA: Predictors of medication self-management skill in a low-literacy population. J Gen Intern Med 2006, 21(8):852-856. 
10. Lee JY, Divaris K, Baker AD, Rozier RG, Lee SY, Vann WF Jr: Oral health literacy levels among a low-income WIC population. J Public Health Dent 2011, 71(2):152-160.

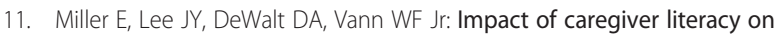
children's oral health outcomes. Pediatrics 2010, 126(1):107-114.

12. Vann WF Jr, Lee JY, Baker D, Divaris K: Oral health literacy among female caregivers: Impact on oral health outcomes in early childhood. $J$ Dent Res 2010, 89(12):1395-1400.

13. Bender BG, Bartlett SJ, Rand CS, Turner C, Wamboldt FS, Zhang L: Impact of interview mode on accuracy of child and parent report of adherence with asthma-controller medication. Pediatrics 2007, 120(3):e471-e477.

14. Phillips DI, Clancy KJ: Some effects of 'social desirability' in survey studies. Amer J Sociol 1972, 77(5):921-940.

15. King MF, Bruner GC: Social desirability bias: a neglected aspect of validity testing. Psychol Market 2000, 17(2):79-103.

16. Nederhof AJ: Methods of coping with social desirability bias: a review. Eur J Soc Psychol 1985, 15(3):263-280.

17. Douglass JM, Tinanoff N, Tang JM, Altman DS: Dental caries patterns and oral health behaviors in Arizona infants and toddlers. Community Dent Oral 2001, 29(1):14-22.

18. Shick EA, Lee JY, Rozier RG: Determinants of dental referral practices among WIC nutritionists in North Carolina. J Public Health Dent 2005, 65(4):196-202.

19. NIDCR Data Resource Center: Oral health questions included in National Oral Health Surveys (September 9, 2009). Available at: http://drc.hhs.gov/ surveyq/index.htm.

20. Lee JY, Rozier RG, Lee SD, Bender D, Ruiz RE: Development of a word recognition instrument to test health literacy in dentistry: the REALD-30 - a brief communication. J Public Health Dent 2007, 67(2):94-98.

21. D'Agostino RB, Belanger A, D'Agostino RB Jr: A suggestion for using powerful and informative tests of normality. Am Statistician 1990, 44(4):316-321.

22. Maldonado G, Greenland S: Simulation study of confounder-selection strategies. Am J Epidemio/ 1993, 138(11):923-936.

23. Cohen J: A coefficient of agreement for nominal scales. Educ Psych Measurement 1960, 20(1):37-46.

24. Sim J, Wright C: The kappa statistic in reliability studies: Use, interpretation, and sample size requirements. Phys Therapy 2005, 85(3):257-268.

25. Aho J, Koushik A, Diakite SL, Loua KM, Nguyen VK, Rashed S: Biological validation of self-reported condom use among sex workers in Guinea. AIDS Behav 2010, 14(6):1287-1293.

26. Hebert JR, Clemow L, Pbert L, Ockene IS, Ockene JK: Social desirability bias in dietary self-report may compromise the validity of dietary intake measures. Int J Epidemiol 1995, 24(2):389-398.

27. Klesges LM, Baranowski T, Beech B, Cullen K, Murray DM, Rochon J, Pratt C: Social desirability bias in self-reported dietary, physical activity and weight concerns measures in 8- to 10-year old African-American girls: results from the Girls Health Enrichment Multisite Studies (GEMS). Prev Med 2004, 38(Suppl):S78-S87.

28. Macalino GE, Celentano DD, Latkin C, Strathdee SA, Vlahov D: Risk behaviors by audio computer-assisted self-interviews among HIVseropositive and HIV-seronegative injection drug users. AIDS Educ Prev 2002, 14(5):367-378.

29. Miller TM, Abdel-Maksoud MF, Crane LA, Marcus AC, Byers TE: Effects of social approval bias on self-reported fruit and vegetable consumption: a randomized controlled trial. Nutr J 2008, 27:7-18.

30. Sjöstrom O, Holst D: Validity of a questionnaire survey: response patterns in different subgroups and the effect of social desirability. Acta Odontol Scand 2002, 60(3):136-140.

31. Heaivilin N, Gerbert B, Page JE, Gibbs JL: Public health surveillance of dental pain via Twitter. J Dent Res 2011, 90(9):1047-1051.

32. Al-Sane M, Bourisly N, Almulla T, Andersson L: Laypeoples' preferred sources of health information on the emergency management of tooth avulsion. Dent Traumatol 2011, 27(6):432-437.

33. Davis TC, Crouch MA, Long SW, Jackson RH, Bates P, George RB, Bairnsfather LE: Rapid assessment of literacy levels of adult primary care patients. Fam Med 1991, 23(6):433-435.
34. Richman JA, Lee JY, Rozier RG, Gong D, Pahel BT, Vann WF Jr: Evaluation of a word recognition instrument to test health literacy in dentistry: the REALD-99. J Pub Health Dent 2007, 67(2):99-104.

35. Davis TC, Long SW, Jackson RH, Mayeaux EJ, George RB, Murphy PW Crouch MA: Rapid estimate of adult literacy in medicine: a shortened screening instrument. Fam Med 1993, 25(6):391-395.

doi:10.1186/1472-6831-13-24

Cite this article as: Sanzone et al:: A cross sectional study examining social desirability bias in caregiver reporting of children's oral health behaviors. BMC Oral Health 2013 13:24.

\section{Submit your next manuscript to BioMed Central and take full advantage of:}

- Convenient online submission

- Thorough peer review

- No space constraints or color figure charges

- Immediate publication on acceptance

- Inclusion in PubMed, CAS, Scopus and Google Scholar

- Research which is freely available for redistribution 